\title{
Computer tomography and surgical correlation in unsafe ear
}

\author{
Dr. Kumaran alias ramesh Colbert, M.S., dnb ${ }^{1}$, Dr. Vintha gupta, dnb ${ }^{2}$, \\ Dr. M. Ravisankar m.s \\ ${ }^{I}$ (Associate Professor\& HOD, Department of Otorhinolaryngology, Indira Gandhi Medical College \& Research \\ Institute (Government of Puducherry Institution), PUDUCHERRY - 605 009, PONDICHERRY UNIVERSITY, \\ INDIA) \\ ${ }^{2}$ (Personnel Physician, National Wide Clinic, Bangalore) \\ ${ }_{3}^{3}$ Assistant Professor ,Department Of Otorhinolaryngology, Sri Manakula Vinayagar Medical College And \\ Hospital ,Madagadipet, PUDUCHERRY - 605 107, PONDICHERRY UNIVERSITY, INDIA)
}

\begin{abstract}
Chronic suppurative otitis media is a potentially serious disease because of its complications usually with unsafe variety. Though modern drugs have made complications increasingly infrequent, they are still encountered. This implies that the underlying otitic disease should be effectively eliminated to prevent occurrence of complication. Aim of our study is to assess the role of computerized tomography scan in patients with CSOM undergoing surgery and to establish the extent of correlation between CT scan findings with per operative findings.

A series of 25 patients was included in this study parameters like extent of cholesteatoma,ossicular status, fallopian canal assessment, tegmen erosion and anatomical variations are assessed. Our results showed preoperative CT scans useful in defining cholesteatoma extent and in determining ossicular status and early identification of complications.
\end{abstract}

Keywords: Chronic suppurative otitis media, computed tomography, cholesteatoma

\section{INTRODUCTION}

Chronic suppurative otitis media (CSOM) is defined as chronic otorrhoea (i.e., >6-12 wk) through a perforated tympanic membrane (TM). Chronic suppuration can occur with or without cholesteatoma, and the clinical history of both conditions can be very similar. Clinical features are otorrhoea and conduction hearing loss of variable severity. They are grouped into two main clinical types ${ }^{(1)}$ Tubo-tympanic or safe type and Attico-antral or unsafe type. Unsafe type is usually associated with cholesteatomatous erosion of the important structures within the skull and therefore has increased risk of complications. Cholesteatoma is a three dimensional epidermal and connective tissue structure usually in the form of a sac and frequently conforming the architecture of the various spaces of middle ear, attic and mastoid. This structure has the capacity from progressive and independent growth at the expense of underlying bone and has the tendency to recur after removal.

Cholesteatoma, according to presumed etiology is classified into two general categories.Congenital and Acquired, Acquired cholesteatoma constitutes $98 \%$ of all cholesteatoms. The vast majority i.e. $82 \%$ of these arises from the 'pars flaccida' and extend medially and superiorly into the "Prussak's space" (2) The proximity of middle ear cleft and mastoid air cells to the intratemporal and intracranial compartments places structures located in these areas at increased risk of impending complications. $78 \%$ of subjects who had complications secondary of COM were found to have cholesteatoma ${ }^{(3)}$. The temporal bone is a complex structure harboring important structures of the ear which are even less than $0.1 \mathrm{~mm}$ in diameter. They are close to the level of resolution power of any imaging technique.Plain simple radiography is simple, fast and inexpensive and produces sharp image of high contrast structures (air, fluid, bone). However high contrast structure can obscure the low contrast structure and superimposition of overlying structures can sometimes be misleading.

CT scan represents a major advance in delineating structures and disease process. It is unique in its ability to display not only the internal body architecture of the skull but also to evaluate the soft tissue components associated with a pathological process. The major advantages of CT over polytomography are ${ }^{[4]}$ 1)Better demonstration of soft tissue structure 2)Better resolution of spatial details 3)A reduced radiation dose to the patient 4)Reconstruction in different planes is possible.High Resolution Computerized Tomography (HRCT) has significantly improved the contribution of imaging in the pre-operative assessment and management of Attico-antral type of csom. in the presence of unsafe ear surgical treatment is the modality of treatment except in elderly and in patients with poor general medical condition (5). The aim of the our study is to assess the role of Computerized Tomography (CT) scan in pre-operative evaluation of unsafe ear. To know the limitations and draw backs of CT scan in evaluating unsafe ear. The objective of the study was to establish the extent of correlation between CT scan findings with per-operative surgical findings. 


\section{Materials And Methods}

This Prospective study was conducted in PSG institute of Medical Sciences \& Research,coimbatore from february 2006 to february 2008. The study population was 25 and the inclusion criteria for these population were 1) Patient with previous ear surgeries 2) Patient with serious systemic diseases 3) Patient unwilling for surgery .Relevant detailed history of all selected patient was obtained with main emphasis on duration of ear discharge, previous medication and surgery, if any. A thorough general and systemic examination was followed by scrupulous ENT examination. All otoscopic findings were confirmed under Oto-microscopy(fig 1) Routine Blood and Urine investigations were carried out as pre-requisite for PreAnesthetic assessment and Surgery. X-Ray Mastoid (Law's view) and (Pure tone Audiometry was performed for all the patients.

All patients underwent High Resolution Computed Tomography (HRTC) of middle ear and Temporal bone using Siemens 64 slice CT scanner. Sections taken were of $1 \mathrm{~mm}$ thickness ${ }^{(6)}$. Axial, Coronal and Saggital sections were taken and contrast study was done wherever indicated. The following structures were studied in the CT scan as they are mainly affected in the disease process.

1. Location and extent of cholesteatoma.

2. State of ossicular chain for any erosion and discontinuity.

3. Fallopian canal for dehiscence.

4. Semi circular canals for dehiscence.

5. Tegmen tympani for any breach.

6. Mastoid Antrum and cavity for erosion.

7. Attic region for erosion of 'Scutum ' and 'Lateral spine'.

8. Sinus plate for erosion and for evidence of thrombosis of sigmoid sinus.

9. Erosion of the postero-superior wall of external auditory meatus.

10. Any other intra / extra cranial extension of diseases process.

All of our patients underwent modified radical mastoidectomy with tympanoplasty under general anesthesia. Granulations and other suspected tissue were biopsied and sent for Histo-Pahtological examination as and when required to establish the diagnosis of cholesteatoma. CT scan findings were confirmed peroperatively with the pre-operative findings to judge the accuracy of CT scan in predicting the extent of disease and clinical findings. Statistical analysis was done using the Kappa Coefficient. kappa coefficient ranged from $0-1 ; 0$ indicate no agreement and 1 indicate complete agreement. Coefficient in the range $<0.2 ; 0.2-0.4 ; 0.4-0.6$; $0.6-0.8$, indicate poor, fair, moderate and good agreement.

\section{OBSERVATIONS AND RESULTS}

A total of 25 cases were studied using 'Axial', 'Coronal' and 'Saggial' sections. All cases presented with CSOM with persistent aural discharge of more than 4 weeks duration. On clinical examination 5 cases had retraction pockets whose fundus was not seen, cholesteatomatous flakes in the posterosuperior quadrant seen in 7 cases and attic granulations were present in 13 cases.

\section{CORRELATION BETWEEN PREOPERATIVE CT AND PEROPERATIVE FINDINGS}

The diagnosis of cholesteatoma is usually made on otological examination. The CT scan demonstrates presence of non-dependent, homogenous, soft tissue mass in a location appropriate to the etiopathogenesis of the lesion, The findings of the present study are tabulated below. (Table 1)

Table 1:

\begin{tabular}{|l|l|c|c|c|}
\hline \multicolumn{5}{|c|}{ CT Findings } \\
\hline & Per OP $\downarrow$ & Normal & Abnormal & Kappa \\
\hline $\begin{array}{l}\text { Non dependent homogenous mass in location typical } \\
\text { for cholesteatoma }\end{array}$ & Absent & 2 & 1 & \\
\cline { 2 - 4 } & Present & 2 & 20 & \multirow{2}{*}{0.623} \\
\hline
\end{tabular}

21 cases showed presence of cholesteatoma on CT while 22 cases were seen to have a cholesteatoma peroperatively. 2 cases were interpreted in CT as having cholesteatoma but per operatively only granulation tissue was seen. Almost $90 \%$ cases had both granulation tissue and cholesteatoms where it was very difficult to differentiate between them. Even contrast enhancement could not differentiate between the two with certainty.

\section{OSSICULAR STATUS}

Erosion of the Incus was the commonest finding with CT scan showing erosion of the Incus in 22 cases. Per-operative observation also showed 22 cases where Incus was eroded(fig 2). However one case which 
showed erosion on CT was found to be free of disease per-operatively and one case in which Incus was found to be eroded per-operatively was reported as normal on CT. In two cases Incus was found to be intact both on CT and per-operatively. Malleus was found involved in 11 cases on CT as well as per-operatively but one case reported as eroded on CT was found intact per-operatively and one case reported normal on CT was found to be eroded per-operatively although minimally. Stapes was found to be the ossicle involved in minimum number of cases. It was found eroded on CT in nine cases while per-operatively only eight cases showed erosion(Table 2).

Our observations showed that Incus, long and short process followed by body, was the most common ossicle to be involved. Body of Malleus showed the next most common involvement. The CT and pre-operative correlation is very good in case of Malleus and Stapes, while it is good in case of Incus as shown by Kappa values of more than 0.8 in the former case and between 0.6 and 0.8 for the latter.

Table 2:

\begin{tabular}{|c|l|c|c|c|}
\hline \multicolumn{2}{|c|}{ CT Findings } & Kappa \\
\hline \multirow{3}{*}{ Malleus } & Per OP $\downarrow$ & Intact & Abnormal & \multirow{2}{*}{0.85} \\
& Intact & 13 & 1 & \multirow{2}{*}{0.749} \\
\cline { 2 - 5 } & Eroded & 1 & 1 & \multirow{2}{*}{0.91} \\
\hline \multirow{2}{*}{ Incus } & Intact & 2 & 1 & \\
\cline { 2 - 5 } & Eroded & 1 & 10 & \\
\hline
\end{tabular}

\section{FALLOPIAN CANAL}

When middle ear is free of disease, the thin lateral wall (bony) of Fallopian canal is easily visualized on CT scan against the dark radiolucent back ground. Of the seven cases with surgically confirmed facial canal dehiscence, only three could be detected on the CT scan. In eighteen cases the facial canal was judged during surgery to be intact, but the scan suggested possible erosion in one case(Table 3). Kappa was calculated as 0.593 implying a moderate correlation between CT and per-operative findings.

Table 3:

\begin{tabular}{|l|l|c|c|c|}
\hline \multicolumn{3}{|c|}{ CT Findings } & Kappa \\
\hline \multirow{2}{*}{ Fallopian Canal } & Per OP $\downarrow$ & Intact & Abnormal & \multirow{2}{*}{0.593} \\
\cline { 2 - 5 } & Intact & 17 & 1 & 3 \\
\hline
\end{tabular}

\section{LABYRINTHINE FISTULA}

In our study, there were four patients with surgically confirmed labyrinthine fistula(fig 4). All four involved the lateral semicircular canal. Three of the four cases were visible in the pre operative scans(fig5), while the remaining case showed thinning of the otic capsule but with no discernible fistula on the scan. Of the remaining twenty one case where semicircular canals were intact preoperatively, the CT scan showed fistulization in one case(Table4).

Table 4:

\begin{tabular}{|l|l|c|c|c|}
\hline \multicolumn{3}{|l|}{ CT Findings } & Kappa \\
\hline \multirow{2}{*}{ labyrinthine fistula } & Per OP $\downarrow$ & Intact & Abnormal & \multirow{2}{*}{0.768} \\
\cline { 2 - 4 } & Intact & 20 & 1 & 3 \\
\hline
\end{tabular}

The correlation between the surgical and CT findings however was good as shown by a Kappa coefficient of 0.768 .

VIII. TEGMEN TYMPANI

The Tegmen is normally visualized on coronal or sagittal section where it appears as a thin bony plate overlying the epitympanum and antrum. One patient had erosion of tegmen(fig 3) exposing dura and this was 
shown with the scan. Of the remaining twenty four cases, the CT scan misread one case as having tegmen dehiscence when there was not any(Table 5).

Table 5:

\begin{tabular}{|l|l|c|c|c|}
\hline \multicolumn{2}{|l|}{ CT Findings } & Kappa \\
\hline \multirow{2}{*}{ Tegmen Tympani } & Per OP $\downarrow$ & Intact & Abnormal & \multirow{2}{*}{0.648} \\
\cline { 2 - 5 } & Intact & 23 & 1 & 1 \\
\hline
\end{tabular}

The Kappa for correlation of surgical and CT scan findings was 0.648 which implies a good correlation.

In addition to the above findings of dehiscent facial canal, labyrinthine fistula and tegmen erosion, various other congenital anatomical variations and surgical hazards were detected in the course of reviewing the scans and included:1)Erosion of posterior canal wall 2)Erosion of sinus plate 3)High and dehiscent jugular bulb4)Anteriorly lying sigmoid sinus5)Low lying dura.

\section{DISCUSSION}

CT has shown enormous development since the original images obtained by Hounsfield in the early 1970s. In 1998 multislice CT scanners, that use multiple detector rows and therefore acquire multiple slices per rotation, were introduced resulting in more speed, volume and detail. CT has proved particularly useful in sinus and middle ear disease as well as evaluating the skull base in combination with MRI.

Cholesteatoma can be diagnosed accurately by the HRCT scan in the vast majority of cases. Mafee et al (7) reported in his series of 48 patients with cholesteatoma of which $46(96 \%)$ were diagnosed correctly with the pre-operative CT scan. In our study 21 out of 23 cases $(92 \%)$ exhibited at least 2 or more radiological features that we associate with cholesteatoma namely tissue mass, typical location and bony erosion. Two cases did not reveal a cholesteatoma however both showed the presence of granulation tissue which could not be identified pre-operatively on CT.

Granulation tissue has been a source of confusion in the various studies done previously as it was misinterpreted as cholesteatoma. Classically it is manifested in three ways soft, fibrous and cholesterol granuloma. It usually presents as a non-dependent mass in a location typical for cholesteatoma, however it may simply present as a large dependent collection as it has a tendency to bleed and thereby causes hemotympanum. This may coexist with cholesteatoma and differentiating the two has rarely been possible at CT as proved by our and other previous studies. ${ }^{(8,9)}$

The HRCT scan has shown a good to excellent radio-surgical correlation for the middle ear ossicles in our cases, and this is also the experience that other authors have reported ${ }^{(7,10,11,12)}$ however some authors have reported poor correlation with stapes as it is not found in almost $40 \%$ of cases of cholesteatoma ${ }^{(13)}$. Due to Partial Volume Averaging there is difficulty in the evaluation of ossicular abnormalities in conjunction with soft mass or small erosion ${ }^{(14)}$. While prior knowledge of the state of the ossicles is probably not critical in so far as the operative risk is concerned, it has bearing on the likelihood of hearing preservation that can be achieved after surgery. Pre-surgical knowledge of the status of the ossicular chain would allow the surgeon to better advise the patient on the degree of hearing attainable after surgery. The scan picture may at times influence the decision and timing of surgical exploration. Scan evidence of cholesteatoma with significant bony destruction or other complications could prompt the surgeon to operate earlier.

Facial canal dehiscence is a fairly common finding in 55\% of temporal bones, and usually occurring in a focal area in the tympanic portion of the fallopian canal ${ }^{(14)}$. Our study however showed surgically confirmed facial canal dehiscence in $7(28 \%)$ cases and but only $3(42.8 \%)$ cases showed dehiscence on the CT scan. This has been also found in other studies $^{(15,16)}$ and occurs due to the fact that the fallopian canal can be so thin even in non pathological ear so as to appear dehiscent, the so called partial volume averaging artifact. This explains the poor radiological correlation with the surgical findings.

Tympanic part of Fallopian canal be visualized more effectively than the vertical part. Some fallacies in CT reporting of Fallopian canal occur due to following reasons:

1. Edema of the surrounding tissue where edematous tissues are normally shown as dehiscence.

2. Thin wall of the fallopian canal, even less than $0.1 \mathrm{~mm}$, where difference in density between the canal and the background density may be insufficient for their visualization.

3. Sometimes when granulation tissue abuts the tympanic portion of the canal, it is difficult to determine whether cholesteatoma has eroded the canal or merely lies adjacent to a congenital defect. 
Labyrinthine fistula can be accurately detected most of the time when both axial and coronal images are taken to look for erosion of the semicircular canals. The most common canal affected is the lateral semicircular canals. The most common canal affected is the lateral semicircular canal and reliance on coronal sections alone may lead to a $50 \%$ false positive rate of dehiscence due to the artifact of partial volume averaging ${ }^{(9)}$.

Tegmen erosion is well seen on coronal imaging, but again misinterpretations may result from partial volume averaging effects ${ }^{(9)}$. Cholesteatoma has tendency to reside in hidden area such as the sinus tympani and the anterior epitympanum. Knowledge of the disease extent and information on the degree of mastoid pneumatisation aid in planning the surgical approach, e.g. whether to keep the canal wall up or down.

\section{CONCLUSION}

Our study has shown very good to moderate correlation between CT scan and per-operative findings. It is an excellent tool in cases where diagnosis of cholesteastoma is doubtful and in case where complications of cholesteatoma are present. It has various advantages as compared to the tomography in the visualization of fallopian canal,to find cholesteatoma in hidden areas like sinus tympani and early identification of complications .CT gives excellent pre-operative information. CT has its own disadvantages like it was unable to distinguish definitely between cholesteatoma and granulation tissue or other pathological / soft tissue with identical radiographic density and difficulties in the evaluation of ossicular abnormalities in conjunction with soft mass or small erosion due to Partial Volume Averaging.

\section{BIBLIOGRAPHY}

[1] Otitis media, In Mawson's Disease of the Ear. Editor: Ludman H, Arnold publisher, London, 1988:403-435

[2] Swartz JD. Cholesteatoma of the middle ear, diagnosis, etiology and complications. The Radiologic clinics of North America, 1984 Vol 22:15-36

[3] Osma U Cureoglu S, Hosoglu S. The complications of chronic otitis media; report cases. J Laryngol Otol 2000; $114(2): 97$ - 100.

[4] Latchow RE, Dreisbacj JN; Imaging the Petrous Bone and associated intracranial structures. In Otolaryngology: Head and Neck Surgery. Editor Cumming CW, Mosby year Book Inc. St. Louis, 1993:2726 - 2728.

Meimaneijahromi A, hoseinnejadariani F,Arabkhani R, hoseein nejadariani Sh. Evaluation of cholesteatoma frequency Patients with chronic otitis media. Iranian jornal of Otolaryngology, 2010;22(59):21-4.

[6] Phelps PD. Radiology of Ear. In, Scott Brown's Otolaryngology Vol3. Editor Booth JB, Butterworth, London, 1987:15-52

[7] Mafee MF, Levein BC, Applebaum EL, Campos M, James CF. Cholesteatoma of the middle ear and mastoid. A comparison of CT scan and operative findings. Otolaryngol Clin North Am 1988; 21:265-92.

[8] Plester D, Steinback E. Cholesterol Granuloma. OCNA, 1982, 15: 665-672.

[9] Robillard T, Syenaeve P, Garnir JJ, Debroux L, Gillaine M. Acta Otorhinolaryngol, Belg, 1992; 46(1): 71-5.

[10] Jackler RK, Dillon WP, Schindler RA. Computed tomography in suppurative ear disease. A correlation of surgical and radiographic findings. Laryngoscope 1984; 94:746-52

[11] O'Donoghue GM, Bates GJ, Anslow P, Rothera MP. The predictive value of high resolution computerized tomography in chronic suppurative ear disease. Clin.Otolaryngol. 1987;12:89-96.

[12] Cook JA, Krishnan S, Fagan PA. Hearing results following modified radical versus canal-up mastoidectomy. Ann Otol Rhinol Laryngol 1996; 105(5):379-83

[13] Rocher P, Carlier R, Attal P, Doyon D, Bobin S. Contribution and Role of Scanner in pre-operative evaluation of chronic Otitis Media. Ann Otolaryngol Chir Cervicifac, 1995; 112(7):317-23

[14] Phelps PD: Radiology of the Ear. In, Scott Brown's Otolaryngology. Vol3. Editor - Booth JB, Butterworth, London, 1987, 15-52.

[15] Johnson DW, Hinshow DB Jr. Hasso et al: Computed Tomography - Local Complications of Temporal Bone Cholesteatoma. J Comput Assist Tomography 1985, 9 (3): 519-523.

[16] NWC Chee, TY Tan. The Value of Pre-operative High Resolution CT Scans in Cholesteatoma Surgery, Singapore Med J, 2001, Vol 42(4): 152 - 159.

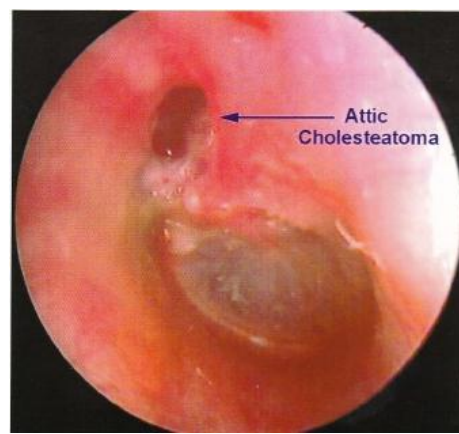

Figure 1

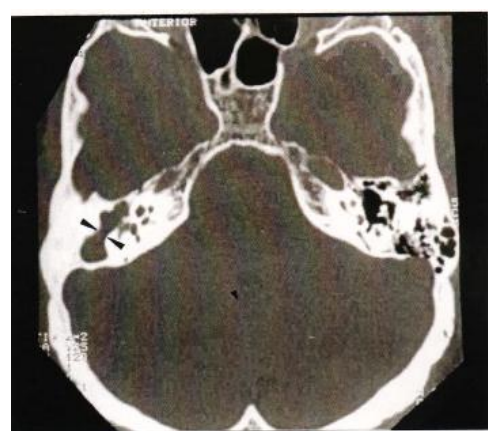

Figure 2 


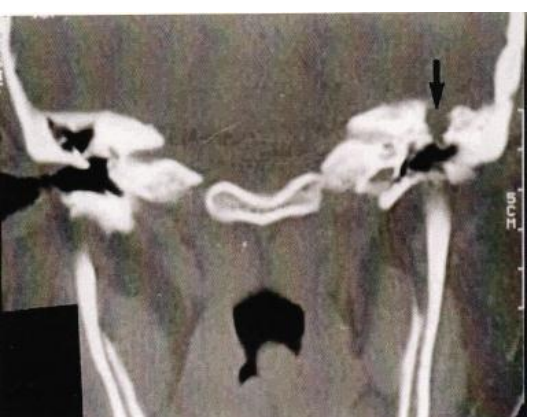

Figure3

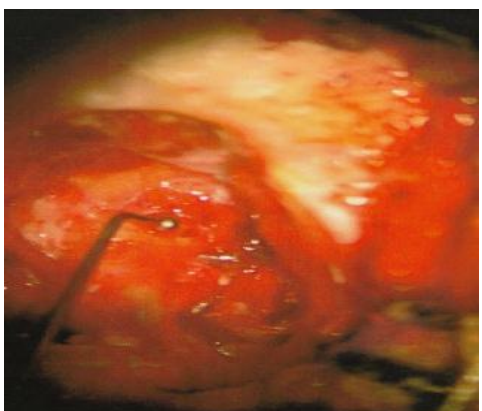

Figure 4

Figure5

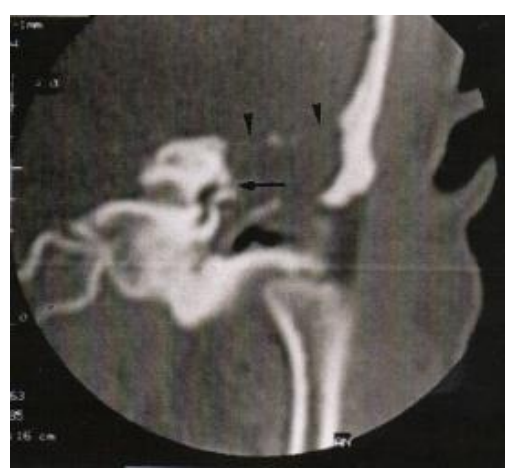

